(C) The Author(s), 2020. Published by Cambridge University Press on behalf of The Nutrition Society. This is an Open Access article, distributed under the terms of the Creative Commons Attribution licence (http://creativecommons.org/licenses/by/4.0/), which permits unrestricted re-use, distribution, and reproduction in any medium, provided the original work is properly cited.

\title{
Obesity and the increased risk for COVID-19: mechanisms and nutritional management
}

\author{
Ana Heloneida de Araújo Morais ${ }^{1,2,3 * \dagger}$ (1) , Thais Sousa Passos ${ }^{3} \dagger$, Sancha Helena de Lima Vale ${ }^{3} \dagger$, \\ Juliana Kelly da Silva Maia ${ }^{1,3} \dagger$ and Bruna Leal Lima Maciel ${ }^{1,3} \dagger$ \\ ${ }^{1}$ Nutrition Postgraduate Program, Centre for Health Sciences, Federal University of Rio Grande do Norte, Natal, RN 59078-970, \\ Brazil \\ ${ }^{2}$ Biochemistry Postgraduate Program, Biosciences Centre, Federal University of Rio Grande do Norte, Natal, RN 59078-970, \\ Brazil \\ ${ }^{3}$ Department of Nutrition, Centre for Health Sciences, Federal University of Rio Grande do Norte, Natal, RN 59078-970, Brazil
}

\begin{abstract}
The global COVID-19 (coronavirus disease 2019) pandemic has become a complex problem that overlaps with a growing public health problem, obesity. Obesity alters different components of the innate and adaptive immune responses, creating a chronic and low-grade state of inflammation. Nutritional status is closely related to a better or worse prognosis of viral infections. Excess weight has been recognised as a risk factor for COVID-19 complications. In addition to the direct risk, obesity triggers other diseases such as diabetes and hypertension, increasing the risk of severe COVID-19. The present review explains the diets that induce obesity and the importance of different foods in this process. We also review tissue disruption in obesity, leading to impaired immune responses and the possible mechanisms by which obesity and its co-morbidities increase COVID-19 morbidity and mortality. Nutritional strategies that support the immune system in patients with obesity and with COVID-19 are also discussed in light of the available data, considering the severity of the infection. The discussions held may contribute to combating this global emergency and planning specific public health policy.
\end{abstract}

Key words: SARS-CoV-2: Coronavirus: Viral infection: Immunity: Nutritional status: Overweight

(Received 23 April 2020; revised 23 October 2020; accepted 10 November 2020; accepted manuscript published online 13 November 2020)

\section{Introduction}

The global pandemic of COVID-19 (coronavirus disease 2019) caused by the SARS-CoV-2 (severe acute respiratory syndrome coronavirus 2) virus is a complex problem affecting society in several aspects, whether economic, social and especially health. There is no doubt that food plays a fundamental role in the population's health-disease processes in general: the impact of nutrition on the immune system is well recognised ${ }^{(1)}$.

Nutritional status is closely related to a better or worse prognosis of a disease, and this finding is no different for viral infections ${ }^{(2)}$, including COVID-19. Various nutrients, whether essential vitamins or minerals and the bioactive compounds found in the most diverse foods, especially in fresh or minimally processed foods, play crucial and complementary roles in supporting the immune system's innate and adaptive processes ${ }^{(3,4)}$. However, the global pattern of food consumption in recent years has been predominantly represented by diets rich in sugars, fats and $\mathrm{Na}$, from ultra-processed industrialised foods ${ }^{(5-7)}$. Despite this, few studies have related the consumption of ultra-processed foods and their respective damage to the immune system ${ }^{(8,9)}$.

According to the FAO the nature of foods, how their choice is driven, and their respective impacts on human health status have been neglected in epidemiological and experimental studies on diet, nutrition and health. However, these preferences have an impact on nutritional status, partially justifying the progressive and sustained increase in obesity cases ${ }^{(10)}$.

Recently, regional boards of the four UN agencies (FAO, UNICEF, WHO and World Food Programme) issued a joint statement on nutrition in the context of the COVID-19 pandemic in Asia and the Pacific. This declaration addresses recommendations for the possible and real impacts of COVID-19 on nutrition, highlighting, among other aspects, the importance of breastfeeding and healthy diets ${ }^{(11)}$.

Obesity has recently been shown to increase the risk for COVID-19 complications, as well as heart disease, diabetes and lung disease $\mathrm{e}^{(12,13)}$. What puts obesity as a critical problem

Abbreviations: ACE, angiotensin-converting enzyme; CCL, chemokine (C-C motif) ligand; COVID-19, coronavirus disease 2019; DIO, diet-induced obesity; ICU, intensive care unit; M1, classical macrophages; PAI-1, plasminogen activator inhibitor-1; SARS-CoV-2, severe acute respiratory syndrome coronavirus 2.

* Corresponding author: Ana Heloneida de Araújo Morais, email aharaujomorais@gmail.com

$\dagger$ These authors contributed equally to the present review. 
is that obesity contributes to systemic metabolic dysfunction and is associated with conditions that increase COVID-19 severity. Individuals with obesity also present with changes in the innate and adaptive immune responses, inducing chronic and lowgrade inflammation ${ }^{(14,15)}$.

Coronaviruses induce an increase in T-helper 1 (Th1) cells, cytokines (IL-1, IL-6), and inflammatory chemokines (chemokine (C-C motif) ligand 2 (CCL2) protein and C-X-C motif chemokine ligand 10 (CXCL10) protein) ${ }^{(16-18)}$. In this sense, there is a need for additional strategies to support the immune system, especially acquired immunity, to reduce the impact of respiratory and other infections.

Considering these immune dysfunctions in patients with COVID-19, management therapies have used immunomodulatory drugs that benefit COVID-19 patients in pathways also altered by obesity ${ }^{(19,20)}$. Hoffmann et al. ${ }^{(21)}$, demonstrated that SARS-CoV-2 uses the SARS-CoV angiotensin-converting enzyme (ACE) 2 receptor to enter the cells and transmembrane protease serine 2 (TMPRSS2) for spike (S) protein priming. According to the study conducted by Sanders et $a l^{(20)}$, some adjuvant therapies on COVID-19 deserve special mention, such as the use of corticosteroids and anti-cytokines. A new mechanism related to the inhibition of a cellular protease FURIN, the transmembrane protease, serine 2, encoded by the TMPRSS 2 gene, is an additional target drug for future research.

Because of the little evidence published so far of efficient vaccines for prevention, and specific and effective drugs to treat COVID-19 ${ }^{(20)}$, challenges arise, such as obesity being among risk factors with significant implications for COVID-19 mortality. These problems are likely to overload health systems that are mostly not well configured to manage patients with obesity ${ }^{(22,23)}$.

Thus, this review presents the health implications of obesity considering the COVID-19 pandemic. We explain diets inducing obesity, and the importance of the different kinds of foods in this process. We review tissue disruption in obesity, leading to impaired immune responses and the possible mechanisms by which obesity and its co-morbidities increase COVID-19 morbidity and mortality. Nutritional strategies that support the immune system in patients with obesity and with COVID-19 are also discussed in light of the available data, considering the severity of the infection for nutritional therapy. The discussions held may contribute to combating this global health emergency, and help the planning of specific public health policy.

\section{Different aspects related to obesity and the COVID-19 pandemic}

Until 2020, obesity was the main pandemic of the 21st century ${ }^{(24-26)}$. Nevertheless, obesity has never received urgent attention, as occurs with the rapid spreading of infectious diseases. Now, the world faces the confluence of two overlapping public health problems: COVID-19 and obesity - with its associated co-morbidities ${ }^{(22)}$

According to the $\mathrm{WHO}^{(27)}$, global obesity has almost tripled since 1975. More alarming data are that, in 2018, 40 million children under 5 years of age were overweight or obese. The USA, the country at the top of the COVID-19 pandemic ranking, is also one of the leaders in the prevalence of obesity ${ }^{(28)}$.

Despite the alarming numbers of overweight and obesity cases, the $\mathrm{WHO}^{(27)}$ considers obesity to be preventable. Classic interventions, with the highest degree of therapeutic recommendation, consist of practising regular physical activity, important in the anti-inflammatory response and reduction of changes in cytokines associated with the strengthening of cellular immune function in obesity ${ }^{(29)}$. Limiting the intake of energy from fats, reducing salt and sugars, and increasing the consumption of vegetables, fruits and whole grains is also essential ${ }^{(27)}$. However, these measures are not easy to adhere to, considering that patients with obesity and its associated morbidities keep increasing in prevalence ${ }^{(30,31)}$.

With the ongoing COVID-19 pandemic, these recommendations have been reinforced by relevant agencies of the UN, which consider that a balanced, diversified and nutritious diet is a crucial way of promoting health and nutritional wellbeing $^{(11)}$. This nutritional care plays a critical role in the immune system $^{(3,4)}$.

Altered microbiota diversity occurs in most individuals with obesity, and a mutual interplay exists between gut microbiota and the immune system ${ }^{(32)}$. According to Morais et al. ${ }^{(33)}$, the administration of probiotics could be a promising adjuvant alternative in the treatment of SARS-CoV-2 infection in addition to adequate intake of nutrients and bioactive compounds from unprocessed food.

Inadequate intake of vitamins and minerals, food processing and industrialisation are related to obesity and the co-regulating of the intestinal microbial ecosystems. Increased energy intake, influenced by lifestyle changes resulting from urbanisation and globalisation, has promoted an obesogenic environment ${ }^{(32,34-38)}$. Although consuming ultra-processed foods is associated with obesity and its co-morbidities ${ }^{(39)}$, only recently studies related this consumption to damage in the immune system ${ }^{(13,14)}$. Cohort studies are also being conducted to clarify the real impact of ultra-processed foods on health ${ }^{(40,41)}$.

Thus, the viability of widespread interventions related to this dietary pattern and their sustainability needs to be evaluated, considering the possibility of generating economic and social impact $^{(30,42)}$. These new interventions should add to the continued adoption of recommendations and strategies aligned with the guidelines given by competent entities in generating data and managing aspects related to nutritional surveillance, food protection, quality of food and food security. These concerns have been raised given COVID-19 ${ }^{(11)}$, as food biodiversity is an opportunity to increase food and nutrition security today ${ }^{(43)}$.

Multisectoral and evidence-based policy actions to deal with the global nutrition crisis have risen. Consequently, obesity has been targeted in several aspects, even though some measures are still unpopular and do not present immediate results. Actions in health systems, economic incentives, concerns about the school and work environment, quality and labelling standards, and innovation, entrepreneurship and sustainability are being implemented ${ }^{(44-47)}$

Overweight and obesity cause other non-communicable diseases that affect the reserves of many nutrients ${ }^{(48-52)}$. Overweight and obesity lead to adverse metabolic effects on blood pressure, 
lipid profile, insulin resistance, low-grade inflammation, and, consequently worse prognosis for viral infections, and this seems to be the same for SARS-CoV-2 $2^{(2,12,13,15)}$.

However, most deaths from non-communicable diseases could be prevented with known behavioural and pharmaceutical interventions. Several initiatives for preventing and controlling non-communicable diseases have been adopted over the last decades, supported by the WHO. These initiatives are currently being tested in the treatment of COVID-19, especially in cases where obesity is also present ${ }^{(15,19,20)}$.

Besides obesity emerging as a significant important risk factor for the severity of COVID-19, the lockdown imposed by COVID19 may also increase the prevalence of obesity ${ }^{(53)}$. For example, most weight-loss programmes and nutritional interventions, such as bariatric surgery, are currently restricted. Additionally, self-isolation measures adopted in some countries will directly affect food consumption at this time of anxiety, and restrict mobility and physical activity. Thus, the effects of increased overweight and obesity may persist for an extended period ${ }^{(54)}$, even considering the alternating isolation. This increase may be especially true in vulnerable populations that already presented food and nutritional insecurity as social-health issues and may worsen the evolution of the COVID-19 pandemic even more $^{(11,55-60)}$

Finally, this global urgency to combat COVID-19 may generate more confidence in processed and industrialised foods compared with fresh food, conditioned by hygienic-sanitary safety, longer shelf life and easier stocking ${ }^{(61)}$. According to Butler \& Barrientos $^{(62)}$ and Muscogiuri et al. ${ }^{(63)}$, it is essential to improve broader access to healthy foods rich in vitamins, minerals, bioactive compounds and antioxidants to reduce susceptibility and long-term complications of COVID-19. Diet composition and obesity have a widespread role in immunity ${ }^{(32)}$, affecting the severity of respiratory diseases and other infections.

\section{Obesity and impaired immune response}

Impaired immune response in individuals with obesity is not a novel feature, and this has been evidenced by high vaccine failure $^{(64)}$ and more complications from infections ${ }^{(65)}$. Worsened response to infections in the presence of obesity was observed in Asian (1957-1960) and Hong Kong (1968) influenzas, leading to higher mortality and prolonged illness duration. The H1N1 pandemic in 2009 was also more severe in patients with obesity, causing more hospitalisations and deaths ${ }^{(66)}$. The same seems to be true for the COVID-19 pandemic $^{(23,66)}$, and there are some immunological explanations for these facts.

One of these explanations underlies the fact that obesity causes stress and dysfunction in many tissues, including the adipose tissue, liver, skeletal muscle, pancreas, gut and respiratory tract. Most of these alterations present an intricate association with inflammation, determined by the immune cells activated in the adipose tissue ${ }^{(14)}$.

Low-grade chronic inflammation, characterised by a higher concentration, in basal levels, of the pro-inflammatory cytokines TNF- $\alpha$, IL-1 $\beta$, monocyte chemoattractant protein-1 (MCP-1) and IL-6, is an obesity hallmark. These cytokines are mainly produced by visceral and subcutaneous adipose tissue-activated macrophages and enlarged adipocytes ${ }^{(67)}$. Classically, this production was considered separately for obesity and pathogens, but now it is accepted that both cause chronic cellular stress, activating shared signalling pathways. The primary difference between these two activations is that the response to pathogens is acute and highly inflammatory. In obesity, the low-grade tissue inflammation provides a physiological immune adaptation. Disruption of this adaptation causes the transition from metabolically healthy obesity to the metabolic syndrome ${ }^{(68)}$.

Although the order of the determining factors for obesityinduced inflammation in humans is not precisely described, animal models have shown that overfeeding causes oxidative stress and an increase in NEFA in the adipose tissue ${ }^{(68)}$. These factors induce the activation of classical macrophages (M1), which are highly inflammatory cells, producing IL- $1 \beta$, TNF- $\alpha$ and IL- 6 . TNF$\alpha$ reduces insulin sensitivity, and the inflammatory cytokines induce more lipolysis with the release of more NEFA, creating an upstream pathway for the inflammation ${ }^{(69)}$.

The enlarging white adipose tissues, in turn, release the CCL2, CCL5 and CCL8 chemokines, which recruit more inflammatory monocytes to the adipose tissue. Concisely, in the absence of obesity, adipose tissue macrophages represent $10-15 \%$ of stromal cells and present markers associated with the maintenance of insulin sensitivity by the production of IL-10. In this context, alternative macrophages (M2) are more activated, producing IL-10 after stimulation by IL- 4 and IL-13. Adiponectin is also higher in lean animals and humans and inhibits the activation of M1. In contrast, during obesity in mice and humans, inflammatory monocytes are recruited to adipose tissue, increasing macrophage content to $45-60 \%{ }^{(14,69)}$.

The inflammation and stress in the adipose tissue induce adipocyte apoptosis and the release of chemotactic mediators. Apoptosis and the chemotactic mediators promote inflammatory leucocyte infiltration. The inflammatory leucocytes produce resistin and IL-1 $\beta$ and induce M1 and adipocytes to produce more TNF- $\alpha$, IL- 6 and monocyte chemoattractant protein-1 (MCP-1), causing a vicious cycle of inflammation ${ }^{(67-69)}$.

These inflammatory alterations in the adipose tissue underlie the chronic systemic inflammation and the metabolic changes in obesity. These changes are mediated, besides insulin resistance, by unfavourable hormone milieu. Low adiponectin (an antiinflammatory adipokine) and high leptin (pro-inflammatory adipokine) production is observed in obesity, ultimately stimulating NF-кB-mediated pro-inflammatory gene transcription and reducing PPAR- $\alpha$ and PPAR- $\gamma$ transcriptional activity. This hormone profile also leads to dysregulation of the immune response and may concur with the obesity-linked complications during infections $^{(70)}$

Obesity also negatively alters the lymphoid tissue structure and function. This impairment occurs by ectopic lipid accumulation in the bone marrow, thymus and secondary lymphoid organs, changing the immune tissue architecture ${ }^{(71,72)}$. This architecture is essential to the development of functional leucocytes through the critical interactions within the immune cells ${ }^{(14)}$. These tissue structure changes alter leucocyte populations' distributions, lymphocyte activity, and immune defences and are linked to a compromised response of innate lymphoid cells ${ }^{(73)}$. 
Interestingly, accumulation of fat tissue in the lymphoid tissues naturally occurs in senescence and impairs immunity in the elderly ${ }^{(74-76)}$. In animal models, energy restriction has been found to block this fat accumulation and is associated with increased immunity and longer lifespan. Thus, obesity can cause premature 'ageing' of the immune system ${ }^{(71,72)}$. This fact may be one of the causes putting individuals with obesity at risk for severe influenza and COVID-19 evolutions, with increased mortality. Further studies should address how immunomodulation induced by diets and other agents could revert the effects of fat accumulation on lymphoid tissues from individuals with obesity and older individuals in the context of SARS-CoV-2 infection.

Obesity alters gut microbiota ${ }^{(67)}$ and several studies have associated oxidative stress with dysbiosis ${ }^{(77,78)}$, which is the disruption of healthy microbiota ${ }^{(79)}$. Evidence suggests that intestinal microflora may be responsible for the development of the low-grade inflammation in obesity. This could possibly occur by microflora dysfunctions in the intestinal barrier, increasing its permeability and inducing endotoxaemia, characterised by an increase in gut-derived plasma lipopolysaccharide ${ }^{(80,81)}$.

Studies in animal models have shown that communication between the gut, adipose tissue and brain is essential for maintaining energy balance. This communication is impaired during obesity and type 2 diabetes $^{(82)}$. In this context, metabolic endotoxaemia has been identified as one of the main factors leading to the development of metabolic inflammation and insulin resistance because the increase in plasma lipopolysaccharide induces $M 1^{(83)}$. The adipokines secreted by the adipose tissue might also affect the airway function. Leptin is involved in neonatal lung development, surfactant production ${ }^{(84,85)}$ and regulation of ventilatory drive ${ }^{(84,86)}$. Studies have consistently shown the association of high leptin concentrations and asthma ${ }^{(87,88)}$.

Considering respiratory infections, most of the knowledge linking obesity and immunity comes from experimental models of influenza ${ }^{(89)}$. In diet-induced obesity (DIO) mice with influenza A infection, impaired host defence was associated with a decrease in type I interferon (IFN- $\alpha$ and IFN- $\beta$ ), a delay in IL-6 and TNF- $\alpha$ expression, that increased to higher concentrations than those in lean animals, and impaired the cytotoxicity of natural killer cells ${ }^{(90)}$. Further studies also revealed that, after influenza infection, DIO reduced dendritic cells' ability to present antigens to T cells, impairing monocyte and $\mathrm{CD} 8^{+} \mathrm{T}$ cell recruitment and reducing IL-2 and IL-12 production $^{(91)}$. DIO mice also demonstrated an inability to produce and maintain functional antigen-specific memory $\mathrm{CD}^{+}{ }^{+} \mathrm{T}$ cells for influenza viruses ${ }^{(92,93)}$. Additionally, effector $\mathrm{CD}^{+}{ }^{+} \mathrm{T}$ cells presented a lower ability to kill influenza-infected cells, and compromised healing of pulmonary epithelial cells, resulting in microvascular permeability and protein leak ${ }^{(89)}$.

Thus, obesity causes stress and disruption of several tissues, with inflammation mainly in the adipose and lymphoid tissues, gut and respiratory tract. The stress and inflammation determine the altered activation of leucocyte subpopulations. These changes impair the immune response, increasing the risk for the evolution of infections to severe disease, and might be the leading causes for increased mortality in patients with obesity and COVID-19 (Fig. 1).

\section{Obesity, co-morbidities and COVID-19: a triple burden}

In addition to disruption of the immune system, obesity can result in metabolic dysfunction leading to dyslipidaemia, insulin resistance, type 2 diabetes, hypertension and CVD, all of which increase patients' vulnerability to SARS-CoV-2 infection ${ }^{(94)}$. Thus, obesity plays a crucial role in the pathogenesis of COVID-19.

Dietz \& Santos-Burgoa ${ }^{(12)}$ suggested that the increased prevalence of obesity in older Italian adults compared with in Chinese could explain the higher COVID-19 mortality in Italy. Studies in both animals and human subjects have shown that obesity is directly related to more severe respiratory infections ${ }^{(89)}$. The H1N1 influenza pandemic (2009) reinforced this evidence since multiple cohort studies showed that obesity and morbid obesity are independent risk factors that increase hospitalisation, admission and time in an intensive care unit (ICU) ${ }^{(95,96)}$. In Spain, a study observed that obesity was the most common co-morbidity (48\%) in patients admitted to ICU with SARS-CoV-2 infection ${ }^{(97)}$.

Although all the possible pathways of interaction between COVID-19 and obesity are still not wholly understood, the discussion concerning the impact of the high prevalence of obesity and coronavirus infection has arisen. Possibly, the interaction between these two important public health concerns occurs through multiple overlapping pathways, some of which will be discussed in this section. Data on this topic are still limiting, and for now, only a few studies have addressed the triple burden of obesity, its co-morbidities and COVID-19 or even other coronavirus diseases. Those data are summarised in Table 1.

Patients with obesity can present compromised pulmonary ventilation dynamics because overweight increases pressure in the diaphragm, making breathing more difficult during infection, promoting a relative increase in the anatomical dead space. Thus, decreased expiratory reserve volume, functional capacity and respiratory system compliance occur ${ }^{(12,66,98)}$. In general, abdominal obesity can impair the ventilation in the lungs' base, resulting in reduced oxygen saturation of the blood $^{(99)}$ and obstructive sleep apnoea associated with an increased risk of CVD and metabolic disease ${ }^{(100)}$. This problem can contribute to daytime alveolar hypoventilation (obesity hypoventilation syndrome) and apparent respiratory failure ${ }^{(101)}$.

Obesity can also contribute to the development of more virulent diseases, and permissive mutations might be triggered by delayed interferon responses that favour viral replication ${ }^{(102)}$. Meliopoulos et $a l^{(103)}$, using an obese mouse model, showed that the lungs of obese mice increased the expression of epithelial integrin 6, which was associated with the severity of lung disease in an influenza virus infection.

Patients with hyperglycaemia and type 2 diabetes have a state of metabolic inflammation, promoting the release of inflammatory cytokines ${ }^{(104)}$. In cases of COVID-19, this condition might be one of the triggering factors to the so-called cytokine storm (a high cytokine release), consequently leading to death due to multiple organ failure. Kulcsar et al. ${ }^{(105)}$ (Table 1), using mice with type 2 diabetes induced by administering a high-fat diet, observed that upon infection with MERS-CoV (Middle East respiratory syndrome coronavirus), diabetic mice had a prolonged phase of severe disease and delayed recovery, regardless of virus titres. These results were attributed to a dysregulated 


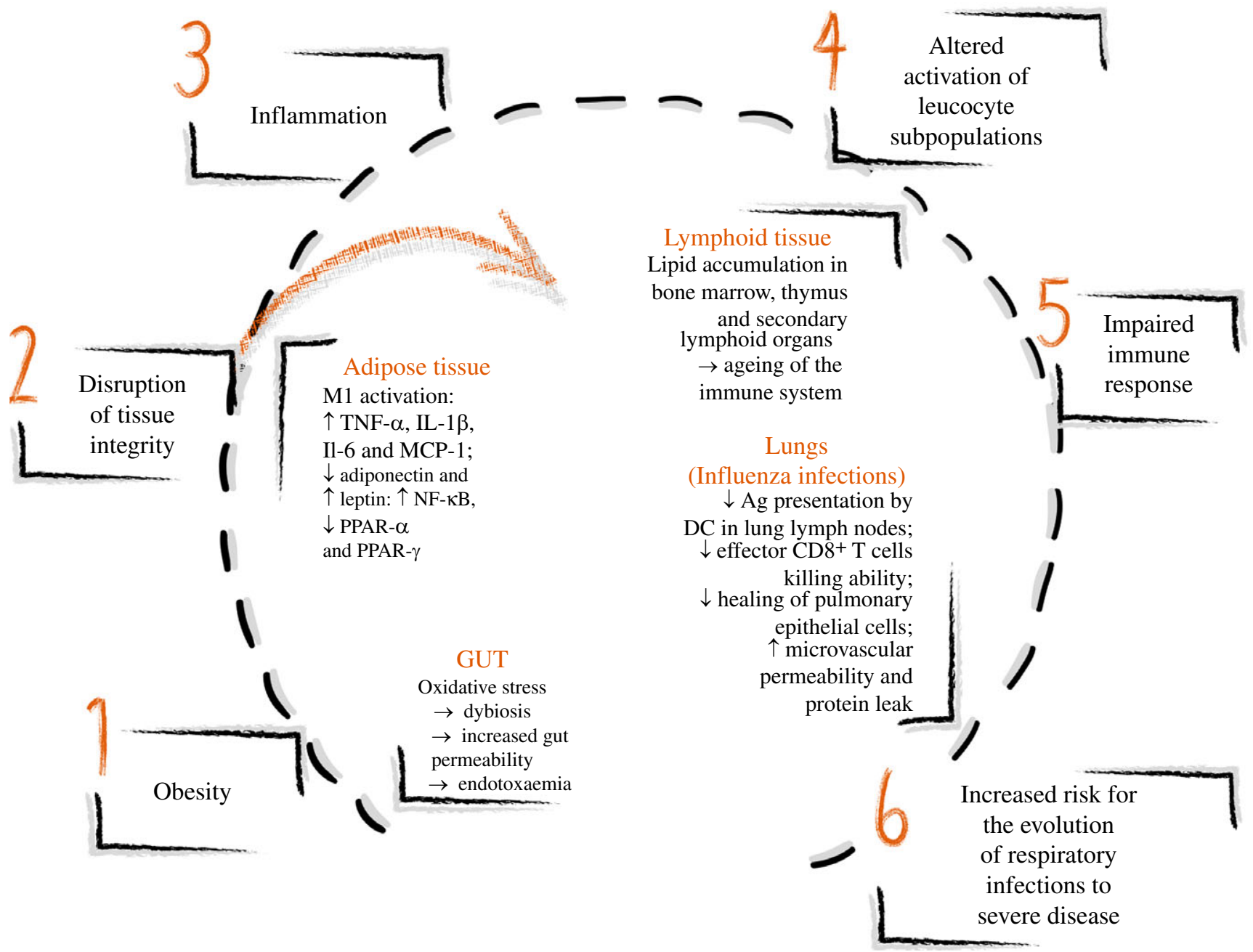

Fig. 1. Obesity and immune alterations in different tissues leading to impaired immune response and increased risk for the evolution of respiratory infectious to severe disease. Obesity determines the stress and disruption of many tissues' integrity leading to inflammation. In the adipose tissue, the enlarging adipocytes present oxidative stress and increase the release of NEFA in the adipose tissue, activating classical macrophages (M1), which produce IL-1 $\beta$, TNF- $\alpha$ and IL-6. An unfavourable hormone milieu also promotes inflammation: low adiponectin and high leptin productions are observed in obesity. In the lymphoid tissue, lipid accumulation occurs in the bone marrow, thymus and secondary lymphoid organs, altering the immune tissue architecture similarly to findings observed in ageing. In the gut, oxidative stress causes dysbiosis, increasing gut permeability and inducing endotoxaemia, characterised by an increase in gut-derived plasma lipopolysaccharide, which induces inflammation. In the lungs, experimental diet-induced obesity studies of influenza infections showed the reduced ability of dendritic cells (DC) to present antigens (Ag) to T cells,

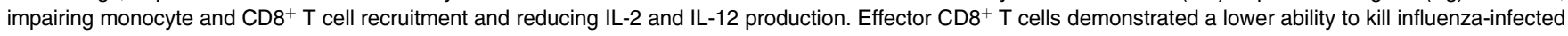
cells, and the healing of pulmonary epithelial cells is compromised, resulting in microvascular permeability and protein leak. Overall, the inflammation induced by obesity causes altered activation of leucocyte subpopulations, impairing the immune response and increasing the risk of the evolution of respiratory infection to severe disease. $\uparrow$, Increase; $\downarrow$, decrease.

immune response, characterised by lower TNF- $\alpha$, IL-6, IL-12b and Arg1 expression levels and higher IL-17a expression levels.

Recently, Hoffmann et al. ${ }^{(21)}$ elucidated that SARS-CoV-2 enters human cells through spike glycoprotein found on the virus's surface. This spike is capable of binding to ACE2, which is expressed in the mouth ${ }^{(106)}$ lung $^{(21)}$, intestine ${ }^{(107)}$ and kidney ${ }^{(108)}$. Studies have already shown that the renin-angiotensin system modulates the metabolism and endocrine function of $\operatorname{adipocytes}^{(109)}$, so this will have significant consequences in patients with obesity infected with SARS-CoV-2.

Bornstein et al. ${ }^{(15)}$ discuss that individuals with insulin resistance or diabetes and hypertension may have this clinical condition aggravated due to an imbalance in the pathways that regulate the activities of ACE1 and ACE2. An increase in the activation of angiotensin receptors (AT1R and AT2R) is promoted, causing higher pro-inflammatory responses, and stimulating aldosterone secretion. As a result, there is an increment in local vascular permeability, which worsens the respiratory syndrome. Besides, type 2 diabetes induces the expression of ACE in tissues other than the lung, such as the liver and heart, so this may contribute to the death of patients due to multiple organ failure in cases of SARS-CoV-2. They observed a high risk to the development of severe hypoxia and death related to the hyperglycaemia and ketosis effects in severe acute respiratory syndrome (SARS) (Table 1).

The clinical condition of patients diagnosed with SARS-CoV-2 worsens more intensely in a pre-existing CVD, related to increased ACE2 secretion ${ }^{(110)}$. As reviewed by Tan \& Aboulhosn ${ }^{(111)}$, several 
Table 1. Studies concerning co-morbidities of obesity and coronavirus infections

\begin{tabular}{|c|c|c|c|}
\hline Reference & Study design & $\begin{array}{l}\text { Co-morbidity } \\
\text { associated } \\
\text { with obesity }\end{array}$ & $\begin{array}{l}\text { Relationship with the worsening prognostic of coronavirus } \\
\text { infections }\end{array}$ \\
\hline Yang et al. ${ }^{(164)}$ & Human study, retrospective analysis & $\begin{array}{l}\text { Hyperglycaemia and } \\
\text { hypertension }\end{array}$ & $\begin{array}{l}\text { Patients admitted to Beijing hospitals diagnosed with } \\
\text { SARS showed increased risk of severe hypoxia and } \\
\text { death risk, due to hyperglycaemia and ketosis effects }\end{array}$ \\
\hline Kulcsar et al. ${ }^{(105)}$ & Mouse model & Type 2 diabetes & $\begin{array}{l}\text { Mice with diabetes showed increased expression of IL- } \\
17 a \text { after infection by MERS-CoV }\end{array}$ \\
\hline Al Heialy et al. ${ }^{(98)}$ & $\begin{array}{l}\text { Re-analysis of publicly available } \\
\text { transcriptomic data and mouse model }\end{array}$ & Diabetes & $\begin{array}{l}\text { Human pulmonary epithelial cells infected with SARS- } \\
\text { CoV-2 presented positive regulation of the suppressor } \\
\text { of the SOC3 gene, which regulates inflammation and } \\
\text { inhibits leptin signalling, favouring viral replication. A } \\
\text { mouse model of diet-induced obesity showed } \\
\text { increased ACE2 expression in the lungs by the } \\
\text { suppression of genes that encode SREBP1 }\end{array}$ \\
\hline Zheng et al. ${ }^{(118)}$ & Human case-control study & MAFLD & $\begin{array}{l}\text { A multi-centre study involving } 214 \text { patients with } \\
\text { laboratory-confirmed COVID-19 aged between } 18 \text { and } \\
75 \text { years of three hospitals in the city of Wenzhou } \\
\text { (China) to investigate the association between MAFLD } \\
\text { and COVID-19 severity. Data showed that the } \\
\text { presence of obesity in patients with MAFLD increased } \\
\text { six-fold the risk for severe COVID-19 }\end{array}$ \\
\hline
\end{tabular}

SARS, severe acute respiratory syndrome; MERS-CoV, Middle East respiratory syndrome coronavirus; SARS-CoV-2, severe acute respiratory syndrome coronavirus 2; SOC3, suppressor of cytokine signalling 3; ACE2, angiotensin-converting enzyme 2; SREBP1, sterol regulatory element-binding protein 1; MAFLD, metabolic associated fatty liver disease; COVID-19, coronavirus disease 2019.

studies have shown that patients with CVD (hypertension and coronary artery disease) require considerable attention in the ICU due to the higher possibility of developing a severe clinical condition of COVID-19.

Obesity and diabetes are directly related to unregulated lipid synthesis and clearance. Al Heialy et al. ${ }^{(98)}$, through the re-analysis of public available transcriptomic data, showed that unregulated lipogenesis leads to high expression of ACE2 in individuals with obesity. This mechanism is consequently related to worse lung injury in SARS-CoV-2 infections (Table 1).

Moreover, abdominal fat is associated with metabolic risk factors that contribute to increased coronary risk. Among these factors are abnormalities in the coagulation system ${ }^{(112)}$. According to the review by Blokhin \& Lentz ${ }^{(113)}$, fibrinolysis is the process of degradation of the fibrin clot by plasmin, whose rate is downregulated by a serine protease inhibitor secreted by the vascular endothelium, liver and adipose tissue called plasminogen activator inhibitor-1 (PAI-1). The expression of the inhibitor undergoes positive regulation in visceral adipose tissue in obesity. According to the review by Blokhin \& Lent ${ }^{(113)}$, high plasma levels of PAI-1 are observed in patients with obesity or the metabolic syndrome. Studies show that TNF- $\alpha$ positively regulates the expression of PAI-1, which suggests that high levels of this activator are related to the chronic inflammatory state of obesity. Preclinical studies demonstrate the association between obesity, high levels of PAI-1, and thrombosis, which reinforces that PAI-1 plays a crucial role in promoting the prothrombotic effects of obesity.

There is an increased risk of disseminated intravascular coagulation and venous thromboembolism as complications in COVID-19 ${ }^{(114)}$, and this may be even worse in patients with obesity. Shock and disseminated intravascular coagulation are associated causes of organ dysfunction in sepsis, and abnormal coagulation has been found in non-survivors of COVID-19. Yin et al. ${ }^{(115)}$ observed that the platelet count in patients with COVID-19 was significantly higher than in the non-COVID group. They attributed this increase to the reactive increase in thrombopoietin after the lung infection, characterising more severe inflammatory reaction and hypercoagulability in COVID-19.

Patients with acute coronary syndrome deserve greater care by specialist clinicians because cardiac functional reserve may be compromised due to myocardial ischaemia or necrosis. When infected with SARS-CoV-2, these patients may have a myocardial infarction (type 1), increased myocardial demand, ischaemia and necrosis, leading to myocardial infarction type 2 . They may also have an increase in the metabolic demand that leads to heart failure and death ${ }^{(110)}$.

According to Kovesdy et al. ${ }^{(116)}$, metabolic changes in obesity might also affect the kidneys through the induction of hypertension and type 2 diabetes. Numerous renal system changes can occur, including ectopic lipid accumulation, increased fat deposition in the renal site, development of glomerular hypertension, increased glomerular permeability due to damage to the glomerular filtration barrier related to hyperfiltration, development of glomerulomegaly, and focal or segmental glomerulosclerosis. Insulin resistance and obesity are also related to the increased risk of developing nephrolithiasis. Body weight is associated with lower urinary $\mathrm{pH}$ and increased urinary oxalate, excretion of acids, $\mathrm{Na}^{+}$and phosphate. Thus, patients with obesity-associated kidney complications may be more severely affected by SARS-CoV-2 infections. Xu et al. ${ }^{(117)}$ were able to locate the expression and distribution of the ACE2 and TMPRSS genes in the renal cells of patients diagnosed with COVID-19, through single-cell transcriptome sequencing (scRNA) analysis. They found that the podocytes and cells of the proximal straight 


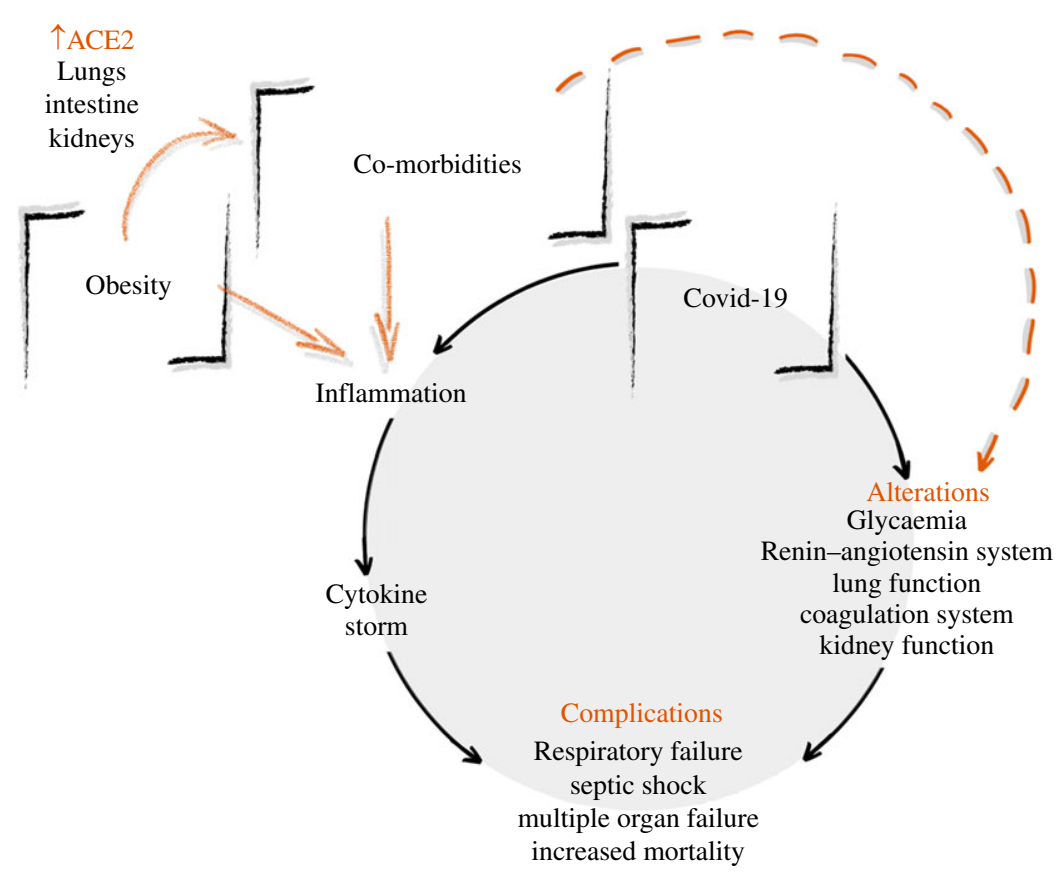

Fig. 2. Obesity, co-morbidities and COVID-19 (coronavirus disease 2019): the triple burden. Obesity and its co-morbidities induce low-grade chronic inflammation and an increase in angiotensin-converting enzyme 2 (ACE2) receptors present in the lungs, intestine and kidneys. COVID-19, in turn, also induces inflammation and alterations overlapping those induced by obesity and its co-morbidities. These alterations occur as the disease severity increases and are in: glycaemia - increasing blood glucose; the renin-angiotensin system - causing higher pro-inflammatory responses; lung function - increasing vascular permeability and lung injury; the coagulation system - increasing prothrombotic effects; kidney function - inducing chronic kidney failure. Possible pathways to explain these worsened alterations in patients with obesity and with co-morbidities are: in the lungs - a higher ACE2 expression, unregulated lipogenesis and inflammation; in the coagulation system - a higher concentration of plasminogen activator inhibitor-1; and in the kidney - a higher expression of ACE2 and transmembrane protease serine (TMPRSS) genes. These overlapping alterations and inflammation associated with the cytokine storm induced by COVID-19 increase the risk of complications in patients with obesity, such as respiratory failure, septic shock, multiple organ failure, and, ultimately, increased mortality.

tubules were infected by SARS-CoV-2, which resulted in chronic kidney failure induced by the virus.

Zheng et al. ${ }^{(118)}$ highlight that patients with metabolic associated non-alcoholic fatty liver disease generally have obesity. As a result, they have metabolic risk factors that may generate a higher risk of respiratory illnesses. Consequently, this can contribute to increased severity of SAR-CoV-2 infection (Table 1).

Thus, obesity and its low-grade chronic inflammation induce the onset of the most diverse co-morbidities. Obesity and its comorbidities, in turn, increase the risk for severe COVID-19. The SARS-CoV-2 infection itself might provoke a broad spectrum of inflammatory responses, aggravating the inflammation of obesity and its co-morbidities and inducing the cytokine storm, characterising the triple burden between obesity, co-morbidities, and COVID-19 that increases mortality (Fig. 2).

\section{Impact of COVID-19 on the nutritional management of obesity}

The first symptoms of COVID-19, such as cough, myalgia, fever and shortness of breath, are similar to other common viral infections $^{(119)}$ and, in general, individuals can be recovering at home. However, patients with obesity should be aware that they may have more complicated clinical courses, as previously discussed.

When presenting with fever, even if not thirsty, COVID-19 patients should continue drinking fluids to support the body's ability to fight the virus and the immune function.
The American Society for Parenteral and Enteral Nutrition (ASPEN) ${ }^{(120)}$ recommends drinking water or clear liquid fluids every hour, at least 3 litres/d, and to monitor for signs of dehydration during COVID-19. There have been reports of olfactory and gustatory dysfunctions, like anosmia and ageusia, in patients with mild-to-moderate SARS-CoV-2 infection ${ }^{(121-123)}$. These symptoms can underlie the loss of appetite, also related as a symptom of COVID-19.

Loss of appetite is a symptom of COVID-19 ${ }^{(123)}$ and has already been linked to inflammation ${ }^{(124)}$. Regardless of age or an individual's BMI, people with a loss of appetite decrease energy and micronutrient consumption ${ }^{(125,126)}$. Nutrients have been extensively related to improvement of the immune status and, consequently, the response to COVID-19. Fresh and minimally processed foods, sources of vitamins C, A, D and E, B vitamins, $n$ - 3 PUFA, Se, Fe and $\mathrm{Zn}$ should be encouraged ${ }^{(4,127)}$. The dietary references intake values of these vitamins and minerals were proposed for healthy individuals by the Institute of Medicine and should be met by the consumption of these foods ${ }^{(128-131)}$.

Evidence suggests that obesity may decrease fat-soluble vitamins and vitamin $C$ concentrations in the plasma ${ }^{(50,132,133)}$. For vitamin A or $\beta$-carotene (vitamin A precursor), this reduction occurs due to a lower intake of these nutrients and/or higher deposition in the adipose tissue, decreasing its bioavailability ${ }^{(134,135)}$.

Vitamin A deficiency has been associated with lower vitamin C concentrations. In a group of 191 patients with the metabolic 
syndrome, vitamin $\mathrm{C}$ deficiency increased 3.5-fold the risk of vitamin A deficiency ${ }^{(50)}$. Vitamin A (or its precursors) can be provided by a large amount of fresh or minimally processed foods, such as milk and dairy products, vegetables, fruits (for example, cantaloupe melon), eggs, and oils ${ }^{(47,136)}$. Males have daily requirements slightly higher than females ${ }^{(129)}$. Citric fruits and dark green vegetables are the main sources of ascorbate in the human diet. One portion of orange, kiwi, guava, cantaloupe melon, broccoli or Brussels sprouts has a minimum of $50 \%$ of the RDA of vitamin $C^{(131,137)}$.

A major source of vitamin D for most humans comes from exposure of the skin to sunlight. Thus, exposure of arms and legs to 0.5 minimal erythemal doses is equivalent to ingesting approximately $3000 \mathrm{IU}(75 \mu \mathrm{g})$ of vitamin $\mathrm{D}_{3}$. Some foods naturally contain vitamin $\mathrm{D}_{2}$ or vitamin $\mathrm{D}_{3}$ (cold water fishes, like sardines, tuna, salmon; egg yolk; shitake mushrooms) and fortified food (milk, butter, cheese, yogurts, breakfast cereal). Pharmaceutical and supplemental sources have different contents of vitamin $\mathrm{D}_{2}$ or $\mathrm{D}_{3}{ }^{(138)}$.

The Endocrine Society Clinical Practice recognises that obesity is associated with vitamin D deficiency and suggests that the daily requirements are higher than the Institute of Medicine values $^{(128)}$, ranging from 1500 to $2000 \mathrm{IU} / \mathrm{d}$ (38 to $\left.50 \mu \mathrm{g} / \mathrm{d}\right)$ and upper-level intakes until $10000 \mathrm{IU} / \mathrm{d}(250 \mu \mathrm{g} / \mathrm{d})^{(138)}$. Vitamin D supplementation to raise serum 25-hydroxyvitamin D (25(OH)D) concentrations at least $40-50 \mathrm{ng} / \mathrm{ml}(100-125 \mathrm{nmol} / \mathrm{l})$ would be an important step in preventing COVID-19 infection and spread $^{(139)}$

The relationship between $\mathrm{Zn}$, obesity and diabetes is well described, showing how this trace element influences lipid and insulin profiles, adiposity, inflammatory processes and insulin resistance ${ }^{(140-143)}$. Recent studies have shown that overweight people and individuals with obesity had lower $\mathrm{Zn}$ serum levels than normal-weight individuals ${ }^{(142,144)}$. These lower $\mathrm{Zn}$ levels in biological fluids have been associated with a higher risk of developing insulin resistance, inflammation, hypertension and hypertriacylglycerolaemia ${ }^{(145)}$. Another study revealed that an energy-restricted diet with $30 \mathrm{mg} / \mathrm{d}$ of $\mathrm{Zn}$ reduced inflammatory markers, insulin resistance, anthropometric measurements and appetite in individuals with obesity ${ }^{(146)}$.

$\mathrm{Zn}$ is in many foods, including meat, fish, oysters, nuts and legumes. Although the absorption varies by substrate, this trace element plays a role as an immunonutrient together with vitamins A, C, E and D, and Se and $\mathrm{Fe}^{(147,148)}$. Besides, high $\mathrm{Zn}^{2+}$ concentrations can mitigate viral RNA replication. A study showed that the replication of RNA-dependent RNA polymerase (RdRp) from coronavirus (SARS-CoV nsp12) was inhibited by increased $\mathrm{Zn}^{2+}$ concentrations ${ }^{(149)}$.

Dysbiosis has been observed in patients infected with COVID-19. Some experiences in managing this alteration have reported the administration of prebiotics and probiotics ${ }^{(150)}$. There is a mutual interaction between obesity, gut microbiota and the adaptive immune system ${ }^{(32,67)}$. These interactions possibly increase the inflammatory status in patients with viral infections, as discussed by Gogokhia et al. ${ }^{(151)}$ in patients with HIV.

Other symptoms of COVID-19 that contribute to the maintenance of overweight and obesity are severe fatigue or myalgia. These can lead to decreased physical activity ${ }^{(152,153)}$. Physical inactivity leads not only to weight gain but also to a loss in immune competence ${ }^{(154,155)}$. Staying home made it more challenging to maintain motivation to a physical activity schedule. For those patients with obesity following nutritional counselling and using medication for co-morbidities and other conditions related to obesity, purchasing healthy food and medicines might be difficult, especially during a lockdown.

The period of social distancing imposed in most countries can be particularly challenging for individuals in treatment for obesity $^{(152,155)}$. For these cases, it is essential to maintain a stock of medicines and groceries ${ }^{(155)}$, and have a fresh food delivery service, so that these items can be replaced more frequently. The amount of contact and support from clinical visits influences motivation to maintain lifestyle changes for weight loss. Teleconference, telehealth and mobile devices may be an effective alternative to provide this patient support and counselling process $^{(154,156)}$. In this social isolation context, sensations that trigger food consumption are also difficult to contain, such as anxiety and depression ${ }^{(155)}$. The boredom caused by the broken routine leads to food craving in an attempt to achieve mood improvement. Therefore, keeping fresh foods and planning meals could help tackle homestay's adverse health effects ${ }^{(63)}$.

In response to the COVID-19 pandemic outbreak, the International Federation for the Surgery of Obesity and Metabolic Disorders (IFSO) postponed all elective surgical and endoscopic bariatric surgery to keep hospital resources available to COVID-19 coping ${ }^{(157)}$. As mentioned, this can negatively affect individuals since following a low-energy diet and medical weight management can be difficult, causing immeasurable impacts on health ${ }^{(158-160)}$. Stahel ${ }^{(160)}$ classified bariatric surgery as elective discretionary that could be postponed for 3 months. Additionally, this author proposed a decision-making algorithm for utilisation during the current COVID-19 pandemic.

The clinical spectrum of the SARS-CoV-2 infection ranges from mild disease with non-specific signs to symptoms of acute respiratory illness ${ }^{(119)}$. In situations of worsening symptoms, individuals must seek medical attention. Currently, several channels are available such as phone calls, chats, videoconferences, where it is possible to consult and ask questions to specialists ${ }^{(156)}$.

However, sometimes the individual must go to a health service for examinations and even for specific hospitalisation care when diagnosed with COVID-19 ${ }^{(119)}$. Hospitalised patients with obesity should be kept on oral feeding whenever possible. Early nutritional supplementation of non-ICU hospitalised patients aims to supply energy and protein that may have its needs increased in situations of infection and inflammation by a coronavirus ${ }^{(126)}$. If oral feeding is not tolerated and/or respiratory conditions require non-invasive ventilation or continuous positive airway pressure, supplemental/total parenteral nutrition may be a choice to avoid complications related to concurrent use of face masks and enteral nutrition ${ }^{(126)}$.

Obesity increases the risk of hospitalisation ${ }^{(154)}$. As previously discussed, in situations of more considerable aggravation, an overreaction of the immune system leading to the lungs' autoimmune aggression could be involved in the most severe acute distress respiratory syndrome ${ }^{(119)}$. Therefore, it may be necessary to continue treatment in ICU, especially for adequate ventilatory support considering the high pulmonary demand characterising COVID-19. 
According to the recent European Society for Parenteral and Enteral Nutrition (ESPEN) guidelines, enteral nutrition may be superior to parenteral nutrition because of a lower risk of infection and is security for patients who receive mechanical ventilation $^{(154)}$. Prone position ventilation is the therapy of choice in acute respiratory distress syndrome patients with obesity ${ }^{(161)}$, and enteral nutrition in this position is not a limitation, being viable and safe.

However, situations such as uncontrolled shock, hypercapnia, acidosis and life-threatening hypoxaemia require a delay in enteral nutrition ${ }^{(162)}$. In cases of impaired enteral nutrition, parenteral nutrition should be suggested. It is vital to consider the target level for blood glucose between 6 and $8 \mathrm{mmol} / 1$, monitoring blood TAG and electrolytes, including phosphate, $\mathrm{K}^{+}$and $\mathrm{Mg}^{2+(154)}$

The best way to determine the energy needs of individuals is indirect calorimetry. If this is not available, Caccialanza et al. ${ }^{(126)}$ suggest that the total amount of energy should be estimated by multiplying the resting energy expenditure calculated by the Harris-Benedict equation by a 1.5 stress-factor (in patients with obesity (BMI $>30 \mathrm{~kg} / \mathrm{m}^{2}$ ), ideal body weight used in the equation), and 1.3 to $1.5 \mathrm{~g}$ of proteins $/ \mathrm{kg}$ of ideal body weight ${ }^{(126,154)}$.

Another option for energy estimation is to use $11-14 \mathrm{kcal} / \mathrm{kg}$ per d (46-59 kJ/kg per d) with actual body weight for critically ill patients with BMI $30-50 \mathrm{~kg} / \mathrm{m}^{2}$, and $22-25 \mathrm{kcal} / \mathrm{kg}$ per d (92-105 $\mathrm{kJ} / \mathrm{kg}$ per d) with ideal body weight for critically ill patients with BMI $>50 \mathrm{~kg} / \mathrm{m}^{2}$, as proposed by Mogensen et al. ${ }^{(163)}$, when analysing patients with obesity and with super-obesity on mechanical breathing. Schetz et al. ${ }^{(161)}$, for energy from non-protein sources, consider an energy ratio from fat and carbohydrates between $30: 70 \%$ (subjects with no respiratory deficiency) to 50:50\% (ventilated patients) ${ }^{(154)}$

Thus, the nutritional management of SARS-CoV-2 infection in patients with obesity, although not fully established yet, must consider the infection's severity. Several nutrients deserve special attention in immunomodulation, such as vitamins A, D and $\mathrm{C}$, and minerals, such as $\mathrm{Zn}$. Prebiotics and probiotics may also be necessary for COVID-19 management, especially in patients with obesity. With the advances of research in the area, health professionals and researchers should establish protocols to ensure proper care.

\section{Final considerations}

The SARS-Cov-2 infection has become pandemic, overlapping with obesity and its co-morbidities. Obesity and its co-morbidities create an unfavourable inflammatory environment that enhances the risk of severe COVID-19. Therefore, obesity must be recognised as an independent risk factor for COVID-19 severity to better define public health policy and protect susceptible individuals, including specific social distancing measures. These measures can also contribute to preventing collapse of the health care system. Further research should define proper therapeutics for COVID-19, and nutritional therapy is an essential measure for treating COVID-19 in patients with obesity. Research should establish protocols, considering the severity of the disease.

\section{Acknowledgements}

The authors thank the Federal University of Rio Grande do Norte (UFRN), especially the Pro-Rectory of Postgraduation and the Pro-Rectory of Research, for all efforts dedicated to supporting the research of our institution.

All the authors contributed equally to this work, with conceptualisation, database research, and drafting and revising the manuscript.

The authors declare no conflicts of interest.

\section{References}

1. Cena H \& Calder PC (2020) Defining a healthy diet: evidence for the role of contemporary dietary patterns in health and disease. Nutrients 12, 334 .

2. Calder PC, Carr AC, Gombart AF, et al. (2020) Optimal nutritional status for a well-functioning immune system is an important factor to protect against viral infections. Nutrients 12, 1181.

3. Childs CE, Calder PC \& Miles EA (2019) Diet and immune function. Nutrients 11, 1933.

4. Zhang L \& Liu Y (2020) Potential interventions for novel coronavirus in China: a systematic review. JMed Virol 92, 479-490.

5. Monteiro CA, Moubarac JC, Cannon G, et al. (2013) Ultraprocessed products are becoming dominant in the global food system. Obes Rev 14, Suppl. 2, 21-28.

6. Monteiro CA, Cannon G, Moubarac JC, et al. (2018) The UN Decade of Nutrition, the NOVA food classification and the trouble with ultra-processing. Public Health Nutr 21, 5-17.

7. Monteiro CA, Cannon G, Levy RB, et al. (2019) Ultraprocessed foods: what they are and how to identify them. Public Health Nutr 22, 936-941.

8. Myles IA (2014) Fast food fever: reviewing the impacts of the Western diet on immunity. Nutr J 13, 61.

9. Gibney MJ, Forde CG, Mullally D, et al. (2017) Ultra-processed foods in human health: a critical appraisal. Am JClin Nutr 106, 717-724.

10. Monteiro C, Cannon G, Lawrence M, et al. (2019) UltraProcessed Foods, Diet Quality, and Health Using the NOVA Classification System. Rome: FAO.

11. United Nations Office for the Coordination of Humanitarian Affairs (OCHA) (2020) Joint statement on nutrition in the context of the COVID-19 pandemic in Asia and the Pacific. https://www.humanitarianresponse.info/en/operations/ bangladesh/document/joint-statement-nutrition-contextcovid-19-pandemic-asia-and-pacific (accessed April 2020).

12. Dietz W \& Santos-Burgoa C (2020) Obesity and its implications for COVID-19 mortality. Obesity 28, 1005.

13. Jordan RE, Adab P \& Cheng KK (2020) Covid-19, risk factors for severe disease and death. BMJ 368, m1198.

14. Andersen CJ, Murphy KE \& Fernandez ML (2016) Impact of obesity and metabolic syndrome on immunity. Adv Nutr 7, 66-75.

15. Bornstein SR, Dalan R, Hopkins D, et al. (2020) Endocrine and metabolic link to coronavirus infection. Nat Rev Endocrinol 16, 297-298.

16. Channappanavar R, Zhao J \& Perlman S (2014) T cell-mediated immune response to respiratory coronaviruses. Immunol Res $\mathbf{5 9}$, 118-128.

17. Mahallawi WH, Khabour OF, Zhang Q, et al. (2018) MERS$\mathrm{CoV}$ infection in humans is associated with a pro-inflammatory Th1 and Th17 cytokine profile. Cytokine 104, 8-13.

18. Mubarak A \& Alturaiki W (2019) Middle East respiratory syndrome coronavirus (MERS-CoV): infection, immunological 
response, and vaccine development. I Immunol Res 2019, 6491738.

19. Mamber S, Krakowka S, Osborn J, et al. (2020) Could unconventional immunomodulatory agents help alleviate COVID-19 symptoms and severity? mSphere 5, e00288-220.

20. Sanders JM, Monogue ML, Jodlowski TZ, et al. (2020) Pharmacologic treatments for coronavirus disease 2019 (COVID-19): a review. JAMA 323, 1824-1836.

21. Hoffmann M, Kleine-Weber H, Schroeder S, et al. (2020) SARS-CoV-2 cell entry depends on ACE2 and TMPRSS2 and is blocked by a clinically proven protease inhibitor. Cell $\mathbf{1 8 1}$, 271-280.

22. Ryan DH \& Ravussin E (2020) COVID 19 and the patient with obesity - the editors speak out. Obesity 28, 847.

23. Simonnet A, Chetboun M, Poissy J, et al. (2020) High prevalence of obesity in severe acute respiratory syndrome coronavirus-2 (SARS-CoV-2) requiring invasive mechanical ventilation. Obesity 28, 1195-1199.

24. National Academies of Sciences, Engineering, and Medicine (2019) Current Status and Response to the Global Obesity Pandemic: Proceedings of a Workshop - In Brief. Washington, DC: The National Academies Press.

25. Swinburn BA, Sacks G, Hall KD, et al. (2011) The global obesity pandemic: shaped by global drivers and local environments. Lancet 378, 804-814.

26. Lee $\mathrm{J}$ (2020) The obesity pandemic and the search for solutions. J Med Food 23, 205.

27. World Health Organization (2020) Obesity and overweight. https://www.who.int/news-room/fact-sheets/detail/obesityand-overweight (accessed May 2020).

28. Centers for Disease Control and Prevention (2020) Centers for Disease Control and Prevention home page. https://www. cdc.gov/ (accessed April 2020).

29. Souza DC, Matos VAF, Dos Santos VOA, et al. (2018) Effects of high-intensity interval and moderate-intensity continuous exercise on inflammatory, leptin, IgA, and lipid peroxidation responses in obese males. Front Physiol 9, 567.

30. Afshin A, Reitsma MB \& Murray CJL (2017) Health effects of overweight and obesity in 195 countries. N Engl J Med 377, 1496-1497.

31. Berry EM (2020) The obesity pandemic - whose responsibility? No blame, no shame, not more of the same. Front Nutr 7, 2.

32. Pindjakova J, Sartini C, Lo Re O, et al. (2017) Gut dysbiosis and adaptive immune response in diet-induced obesity vs. systemic inflammation. Front Microbiol 8, 1157.

33. Morais AHA, Passos TS, Maciel BLL, et al. (2020) Can probiotics and diet promote beneficial immune modulation and purine control in coronavirus infection? Nutrients 12, 1737.

34. Monteiro C \& Cannon G (2019) The role of the transnational ultra-processed food industry in the pandemic of obesity and its associated diseases: problems and solutions. World Nutr J 10, 89-99.

35. Rauber F, Steele EM \& Louzada MLDC, et al. (2020) Ultra-processed food consumption and indicators of obesity in the United Kingdom population (2008-2016). PLOS ONE 15, e0232676.

36. Araújo C, Ribeiro K, Padrão P, et al. (2019) Industrialized foods in early infancy: a growing need of nutritional research. Porto Biomed J4, e47.

37. Fox A \& Feng W (2019) What is driving global obesity trends? Globalization or "modernization"? Global Health 15, 32.

38. Falcao R, Lyra CO, Morais CMM, et al. (2019) Processed and ultra-processed foods are associated with high prevalence of inadequate selenium intake and low prevalence of vitamin $B_{1}$ and zinc inadequacy in adolescents from public schools in an urban area of northeastern Brazil. PLOS ONE 14, e0224984.

39. Chazelas E, Srour B, Desmetz E, et al. (2019) Sugary drink consumption and risk of cancer: results from NutriNet-Sante prospective cohort. BMJ 366, 12408.

40. Silva FM, Giatti L, de Figueiredo RC, et al. (2018) Consumption of ultra-processed food and obesity: cross sectional results from the Brazilian Longitudinal Study of Adult Health (ELSABrasil) cohort (2008-2010). Public Health Nutr 21, 2271-2279.

41. Medeiros G, Azevedo KPM, Mesquita GXB, et al. (2019) Red meat consumption, risk of incidence of cardiovascular disease and cardiovascular mortality, and the dose-response effect: protocol for a systematic review and meta-analysis of longitudinal cohort studies. Medicine (Baltimore) 98, e17271.

42. Dietz WH (2019) Global shifts in the patterns of urban and rural weight increase. Nat Med 25, 1035-1036.

43. Jacob M, Medeiros M \& Albuquerque U (2020) Biodiverse food plants in the semiarid region of Brazil have unknown potential: a systematic review. PLOS ONE 15, e0230936.

44. Bezerra IW, Oliveira AG, Pinheiro LG, et al. (2017) Evaluation of the nutritional status of workers of transformation industries adherent to the Brazilian Workers' Food Program. A comparative study. PLOS ONE 12, e0171821.

45. Mozaffarian D (2020) Dietary and policy priorities to reduce the global crises of obesity and diabetes. Nat Food $\mathbf{1}, 38-50$.

46. Resnick D (2020) Political economy of food system reform. Nat Food 1, 154.

47. da Cunha JA, Rolim PM, Damasceno K, et al. (2020) From seed to flour: sowing sustainability in the use of cantaloupe melon residue (Cucumis melo L. var. reticulatus). PLOS ONE $\mathbf{1 5}$, e0219229.

48. Aquino SLS, da Cunha ATO, Pereira HT, et al. (2018) Predictors of 25-hydroxyvitamin D status among individuals with metabolic syndrome: a cross-sectional study. Diabetol Metab Syndr 10, 45

49. Sales MC, de Oliveira LP, de Araujo Cabral NL, et al. (2018) Plasma zinc in institutionalized elderly individuals: relation with immune and cardiometabolic biomarkers. J Trace Elem Med Biol 50, 615-621.

50. Godala M, Materek-Kusmierkiewicz I, Moczulski D, et al. (2017) The risk of plasma vitamin A, C, E and D deficiency in patients with metabolic syndrome: a case-control study. Adv Clin Exp Med 26, 581-586.

51. Freitas EP, Cunha AT, Aquino SL, et al. (2017) Zinc status biomarkers and cardiometabolic risk factors in metabolic syndrome: a case control study. Nutrients $\mathbf{9}, 175$.

52. Cunha ATO, Pereira HT, de Aquino SLS, et al. (2016) Inadequacies in the habitual nutrient intakes of patients with metabolic syndrome: a cross-sectional study. Diabetol Metab Syndr $\mathbf{8}, 32$.

53. Hellewell J, Abbott S, Gimma A, et al. (2020) Feasibility of controlling COVID-19 outbreaks by isolation of cases and contacts. Lancet Global Health 8, e488-e496.

54. Kissler S, Tedijanto C, Goldstein E, et al. (2020) Projecting the transmission dynamics of SARS-CoV-2 through the postpandemic period. Science 368, 860-868

55. Calazans DLMS, Pequeno NPF, Camara JPT, et al. (2017) Analysis of the human right to adequate food of the indigenous of Sagi-Trabanda in Rio Grande do Norte. Interface (Natal) 14, 119-144.

56. Food and Agriculture Organization of the United Nations (2020) Indigenous peoples' health and safety at risk due to Coronavirus (COVID-19). http://www.fao.org/indigenous-peoples/newsarticle/en/c/1268353/ (accessed November 2020).

57. Farrell P, Thow AM, Abimbola S, et al. (2018) How food insecurity could lead to obesity in LMICs: when not enough is too 
much: a realist review of how food insecurity could lead to obesity in low- and middle-income countries. Health Promot Int 33, 812-826.

58. Berger ZD, Evans NG, Phelan AL, et al. (2020) Covid-19: control measures must be equitable and inclusive. BMJ 368, m1141.

59. Rundle AG, Park Y, Herbstman JB, et al. (2020) COVID-19related school closings and risk of weight gain among children. Obesity 28, 1008-1009.

60. Ribeiro KDDS, Garcia LRS, Dametto JFDS, et al. (2020) COVID-19 and nutrition: the need for initiatives to promote healthy eating and prevent obesity in childhood. Child Obes 16, 235-237

61. UNSCN (United Nations System Standing Committee on Nutrition) (2020) Food Environments in the COVID-19 pandemic: last updated by the UNSCN Secretariat on 8th April. https://www.unscn.org/en/news-events/recent-news?idnews= 2040 (accessed May 2020).

62. Butler MJ \& Barrientos RM (2020) The impact of nutrition on COVID-19 susceptibility and long-term consequences. Brain Behav Immun 87, 53-54.

63. Muscogiuri G, Barrea L, Savastano S, et al. (2020) Nutritional recommendations for CoVID-19 quarantine. Eur J Clin Nutr 74, 850-851.

64. Sheridan PA, Paich HA, Handy J, et al. (2012) Obesity is associated with impaired immune response to influenza vaccination in humans. Int J Obes (Lond) 36, 1072-1077.

65. Bandaru P, Rajkumar H \& Nappanveettil G (2013) The impact of obesity on immune response to infection and vaccine: an insight into plausible mechanisms. Endocrinol Metab Synd 2, 10000113.

66. Luzi L \& Radaelli MG (2020) Influenza and obesity: its odd relationship and the lessons for COVID-19 pandemic. Acta Diabetol 57, 759-764.

67. Cox AJ, West NP \& Cripps AW (2015) Obesity, inflammation, and the gut microbiota. Lancet Diabetes Endocrinol 3, 207-215.

68. Thomas D \& Apovian C (2017) Macrophage functions in lean and obese adipose tissue. Metabolism 72, 120-143.

69. Wynn TA, Chawla A \& Pollard JW (2013) Macrophage biology in development, homeostasis and disease. Nature 496, 445-455.

70. Ouchi N, Parker JL, Lugus JJ, et al. (2011) Adipokines in inflammation and metabolic disease. Nat Rev Immunol 11, 85-97.

71. Yang H, Youm YH, Vandanmagsar B, et al. (2009) Obesity accelerates thymic aging. Blood 114, 3803-3812.

72. Kanneganti TD \& Dixit VD (2012) Immunological complications of obesity. Nat Immunol 13, 707-712.

73. Rolot M \& O'Sullivan TE (2020) Living with yourself: innate lymphoid cell immunometabolism. Cells $\mathbf{9}, 334$.

74. Camell CD, Günther P, Lee A, et al. (2019) Aging induces an Nlrp3 inflammasome-dependent expansion of adipose B cells that impairs metabolic homeostasis. Cell Metab 30, 1024-1039.

75. Dixit VD (2012) Impact of immune-metabolic interactions on age-related thymic demise and $\mathrm{T}$ cell senescence. Semin Immunol 24, 321-330.

76. Dixit VD (2008) Adipose-immune interactions during obesity and caloric restriction: reciprocal mechanisms regulating immunity and health span. J Leukoc Biol 84, 882-892.

77. Silva-Maia JK, Batista AG, Correa LC, et al. (2019) Aqueous extract of berry (Plinia jaboticaba) byproduct modulates gut microbiota and maintains the balance on antioxidant defense system in rats. J Food Biochem 43, e12705.

78. Weiss GA \& Hennet T (2017) Mechanisms and consequences of intestinal dysbiosis. Cell Mol Life Sci 74, 2959-2977.

79. Lazar V, Ditu LM, Pircalabioru GG, et al. (2019) Gut microbiota, host organism, and diet trialogue in diabetes and obesity. Front Nutr 6, 21.
80. Cani PD, Osto M, Geurts L, et al. (2012) Involvement of gut microbiota in the development of low-grade inflammation and type 2 diabetes associated with obesity. Gut Microbes 3, 279-288.

81. Cani PD, Possemiers S, Van de Wiele T, et al. (2009) Changes in gut microbiota control inflammation in obese mice through a mechanism involving GLP-2-driven improvement of gut permeability. Gut 58, 1091-1103.

82. Geurts L, Neyrinck AM, Delzenne NM, et al. (2014) Gut microbiota controls adipose tissue expansion, gut barrier and glucose metabolism: novel insights into molecular targets and interventions using prebiotics. Benef Microbes 5, 3-17.

83. Boutagy NE, McMillan RP, Frisard MI, et al. (2016) Metabolic endotoxemia with obesity: is it real and is it relevant? Biochimie 124, 11-20.

84. Torday JS, Powell FL, Farmer CG, et al. (2010) Leptin integrates vertebrate evolution: from oxygen to the blood-gas barrier. Respir Physiol Neurobiol 173, Suppl., S37-S42.

85. De Blasio MJ, Boije M, Kempster SL, et al. (2016) Leptin matures aspects of lung structure and function in the ovine fetus. Endocrinology 157, 395-404.

86. Bassi M, Furuya WI, Menani JV, et al. (2014) Leptin into the ventrolateral medulla facilitates chemorespiratory response in leptin-deficient (ob/ob) mice. Acta Physiol (Oxf) 211, 240-248.

87. Sideleva O, Suratt BT, Black KE, et al. (2012) Obesity and asthma: an inflammatory disease of adipose tissue not the airway. Am J Respir Crit Care Med 186, 598-605.

88. Sood A, Ford ES \& Camargo CA Jr (2006) Association between leptin and asthma in adults. Thorax 61, 300-305.

89. Mancuso P (2013) Obesity and respiratory infections: does excess adiposity weigh down host defense? Pulm Pharmacol Ther 26, 412-419.

90. Smith AG, Sheridan PA, Harp JB, et al. (2007) Diet-induced obese mice have increased mortality and altered immune responses when infected with influenza virus. J Nutr 137, 1236-1243.

91. Smith AG, Sheridan PA, Tseng RJ, et al. (2009) Selective impairment in dendritic cell function and altered antigenspecific $\mathrm{CD}^{+} \mathrm{T}$-cell responses in diet-induced obese mice infected with influenza virus. Immunology 126, 268-279.

92. Karlsson EA, Sheridan PA \& Beck MA (2010) Diet-induced obesity in mice reduces the maintenance of influenza-specific CD8+ memory T cells. J Nutr 140, 1691-1697.

93. Karlsson EA, Sheridan PA \& Beck MA (2010) Diet-induced obesity impairs the $\mathrm{T}$ cell memory response to influenza virus infection. J Immunol 184, 3127-3133.

94. Kassir R (2020) Risk of COVID-19 for patients with obesity. Obes Rev 21, e13034.

95. Hanslik T, Boelle P-Y \& Flahault A (2010) Preliminary estimation of risk factors for admission to intensive care units and for death in patients infected with A(H1N1)2009 influenza virus, France, 2009-2010. PLoS Curr 2, RRN1150.

96. Morgan OW, Bramley A, Fowlkes A, et al. (2010) Morbid obesity as a risk factor for hospitalization and death due to 2009 pandemic influenza A(H1N1) disease. PLOS ONE 5, e9694.

97. Barrasa H, Rello J, Tejada S, et al. (2020) SARS-Cov-2 in Spanish intensive care: early experience with 15-day survival in Vitoria. Anaesth Crit Care Pain Med 39, 553-561.

98. Al Heialy S, Hachim MY, Senok A, et al. (2020) Regulation of angiotensin converting enzyme 2 (ACE2) in obesity: implications for COVID-19. bioRxiv 4, 046938.

99. Dixon AE \& Peters U (2018) The effect of obesity on lung function. Expert Rev Respir Med 12, 755-767.

100. Gottlieb DJ \& Punjabi NM (2020) Diagnosis and management of obstructive sleep apnea: a review. JAMA 323, 1389-1400. 
101. Schwartz AR, Patil SP, Laffan AM, et al. (2008) Obesity and obstructive sleep apnea. Proc Am Thorac Soc 5, 185-192.

102. Honce R \& Karlsson EA (2020) Obesity-related microenvironment promotes emergence of virulent influenza virus strains. mBio 11, e03341-19.

103. Meliopoulos V, Livingston B, Van de Velde LA, et al. (2019) Absence of $\beta 6$ integrin reduces influenza disease severity in highly susceptible obese mice. J Virol 93, e01646-18.

104. Mehta P, McAuley DF, Brown M, et al. (2020) COVID-19: consider cytokine storm syndromes and immunosuppression. Lancet 395, 1033-1034.

105. Kulcsar KA, Coleman CM, Beck SE, et al. (2019) Comorbid diabetes results in immune dysregulation and enhanced disease severity following MERS-CoV infection. JCI Insight 4, e131774.

106. Xu H, Zhong L, Deng J, et al. (2020) High expression of ACE2 receptor of 2019-nCoV on the epithelial cells of oral mucosa. Int J Oral Sci 12, 8.

107. Wang J, Zhao S, Liu M, et al. (2020) ACE2 expression by colonic epithelial cells is associated with viral infection, immunity and energy metabolism. medRxiv 2020, 20020545.

108. Fan C, Li K, Ding Y, et al. (2020) ACE2 expression in kidney and testis may cause kidney and testis damage after 2019nCoV infection. medRxiv 2020, 20022418.

109. Engeli S, Negrel R \& Sharma AM (2000) Physiology and pathophysiology of the adipose tissue renin-angiotensin system. Hypertension 35, 1270-1277.

110. Zheng Y-Y, Ma Y-T, Zhang J-Y, et al. (2020) COVID-19 and the cardiovascular system. Nat Rev Cardiol 17, 259-260.

111. Tan W \& Aboulhosn J (2020) The cardiovascular burden of coronavirus disease 2019 (COVID-19) with a focus on congenital heart disease. Int J Cardiol 309, 70-77.

112. Von Eyben FE, Mouritsen E, Holm J, et al. (2003) Intraabdominal obesity and metabolic risk factors: a study of young adults. Int J Obes Relat Metab Disord 27, 941-949.

113. Blokhin IO \& Lentz SR (2013) Mechanisms of thrombosis in obesity. Curr Opin Hematol 20, 437-444.

114. Kollias A, Kyriakoulis KG, Dimakakos E, et al. (2020) Thromboembolic risk and anticoagulant therapy in COVID19 patients: emerging evidence and call for action. $\mathrm{Br} J$ Haematol 189, 846-847.

115. Yin S, Huang M, Li D, et al. (2020) Difference of coagulation features between severe pneumonia induced by SARS-CoV2 and non-SARS-CoV2. J Thromb Thrombolysis (epublication ahead of print version 3 April 2020).

116. Kovesdy CP, Furth SL \& Zoccali C (2017) Obesity and kidney disease: hidden consequences of the epidemic. Indian $J$ Nephrol 27, 85-92.

117. Xu D, Zhang H, Gong H, et al. (2020) Identification of a potential mechanism of acute kidney injury during the Covid-19 outbreak: a study based on single-cell transcriptome analysis. Preprints 2020, 2020020331.

118. Zheng KI, Gao F, Wang X-B, et al. (2020) Obesity as a risk factor for greater severity of COVID-19 in patients with metabolic associated fatty liver disease. Metabolism 108, 154244.

119. Puig-Domingo M, Marazuela M \& Giustina A (2020) COVID-19 and endocrine diseases. A statement from the European Society of Endocrinology. Endocrine 68, 2-5.

120. American Society for Parenteral and Enteral Nutrition (ASPEN) (2020) Nutrition and Hydration: Quick Facts for COVID-19 Patients. ASPEN Recommendations for Non-ICU COVID-19 Patients. Silver Spring, MD: ASPEN.

121. Russell B, Moss C, Rigg A, et al. (2020) Anosmia and ageusia are emerging as symptoms in patients with COVID-19: what does the current evidence say? Ecancermedicalscience 14, ed98.
122. Vaira LA, Salzano G, Deiana G, et al. (2020) Anosmia and ageusia: common findings in COVID-19 patients. Laryngoscope $103,1787$.

123. Lechien JR, Chiesa-Estomba CM, De Siati DR, et al. (2020) Olfactory and gustatory dysfunctions as a clinical presentation of mild-to-moderate forms of the coronavirus disease (COVID-19): a multicenter European study. Eur Arch Otorbinolaryngol 277, 2251-2261.

124. Sieske L, Janssen G, Babel N, et al. (2019) Inflammation, appetite and food intake in older hospitalized patients. Nutrients 11, 1986.

125. Dent E, Hoogendijk EO \& Wright ORL (2019) New insights into the anorexia of ageing: from prevention to treatment. Curr Opin Clin Nutr Metab Care 22, 44-51.

126. Caccialanza R, Laviano A, Lobascio F, et al. (2020) Early nutritional supplementation in non-critically ill patients hospitalized for the 2019 novel coronavirus disease (COVID-19): rationale and feasibility of a shared pragmatic protocol. Nutrition 74, 110835.

127. Ellulu MS (2017) Obesity, cardiovascular disease, and role of vitamin $\mathrm{C}$ on inflammation: a review of facts and underlying mechanisms. Inflammopharmacology 25, 313-328.

128. Institute of Medicine (2011) Dietary Reference Intakes for Calcium and Vitamin D. Washington, DC: National Academies Press.

129. Institute of Medicine (2001) Dietary Reference Intakes for Vitamin A, Vitamin K, Arsenic, Boron, Chromium, Copper, Iodine, Iron, Manganese, Molybdenum, Nickel, Silicon, Vanadium, and Zinc. Washington, DC: National Academies Press.

130. Institute of Medicine (2011) Dietary Reference Intakes for Thiamin, Riboflavin, Niacin, Vitamin B6, Folate, Vitamin B12, Pantothenic Acid, Biotin, and Choline. Washington, DC: National Academies Press.

131. Institute of Medicine (2011) Dietary Reference Intakes for Vitamin C, Vitamin E, Selenium, and Carotenoids. Washington, DC: National Academies Press.

132. Wortsman J, Matsuoka LY, Chen TC, et al. (2000) Decreased bioavailability of vitamin D in obesity. Am J Clin Nutr 72, 690-693.

133. Amin MN, Siddiqui SA, Uddin MG, et al. (2020) Increased oxidative stress, altered trace elements, and macro-minerals are associated with female obesity. Biol Trace Elem Res 197, 384-393.

134. Beydoun MA, Chen X, Jha K, et al. (2019) Carotenoids, vitamin $\mathrm{A}$, and their association with the metabolic syndrome: a systematic review and meta-analysis. Nutr Rev 77, 32-45.

135. Coronel J \& Pinos I (2019) $\beta$-Carotene in obesity research: technical considerations and current status of the field. Nutrients 11, 842.

136. Medeiros A, Gomes CC, Amaral M, et al. (2019) Nanoencapsulation improved water solubility and color stability of carotenoids extracted from Cantaloupe melon (Cucumis melo L.). Food Chem 270, 562-572.

137. Fenech M, Amaya I, Valpuesta V, et al. (2019) Vitamin C content in fruits: biosynthesis and regulation. Front Plant Sci 9, 2006.

138. Holick MF, Binkley NC, Bischoff-Ferrari HA, et al. (2011) Evaluation, treatment, and prevention of vitamin D deficiency: an Endocrine Society clinical practice guideline. J Clin Endocrinol Metab 96, 1911-1930.

139. Grant WB, Lahore H, McDonnell SL, et al. (2020) Evidence that vitamin D supplementation could reduce risk of influenza and COVID-19 infections and deaths. Nutrients 12, 988.

140. Prasad AS (2012) Discovery of human zinc deficiency: 50 years later. J Trace Elem Med Biol 26, 66-69. 
141. Gombart AF, Pierre A \& Maggini S (2020) A review of micronutrients and the immune system - working in harmony to reduce the risk of infection. Nutrients 12, 236.

142. Rios-Lugo MJ \& Madrigal-Arellano C (2020) Association of serum zinc levels in overweight and obesity. Biol Trace Elem Res 198, 51-57.

143. Lais LL, de Lima Vale SH, Xavier CA, et al. (2016) Effect of a one-week balanced diet on expression of genes related to zinc metabolism and inflammation in type 2 diabetic patients. Clin Nutr Res 5, 26-32.

144. Gu K, Xiang W, Zhang Y, et al. (2019) The association between serum zinc level and overweight/obesity: a metaanalysis. Eur J Nutr 58, 2971-2982.

145. Olechnowicz J, Tinkov A, Skalny A, et al. (2018) Zinc status is associated with inflammation, oxidative stress, lipid, and glucose metabolism. J Physiol Sci 68, 19-31.

146. Khorsandi H, Nikpayam O, Yousefi R, et al. (2019) Zinc supplementation improves body weight management, inflammatory biomarkers and insulin resistance in individuals with obesity: a randomized, placebo-controlled, double-blind trial. Diabetol Metab Syndr 11, 101.

147. Maxfield L \& Crane JS (2019) Zinc deficiency. https://www. ncbi.nlm.nih.gov/books/NBK493231/ (accessed May 2020).

148. Reddavide R, Rotolo O, Caruso MG, et al. (2018) The role of diet in the prevention and treatment of inflammatory bowel diseases. Acta Biomed 89, 60-75.

149. Te Velthuis AJ, Van den Worm SH, Sims AC, et al. (2010) $\mathrm{Zn}^{2+}$ inhibits coronavirus and arterivirus RNA polymerase activity in vitro and zinc ionophores block the replication of these viruses in cell culture. PLOS Pathog 6, e1001176.

150. Xu K, Cai H, Shen Y, et al. (2020) Management of corona virus disease-19 (COVID-19): the Zhejiang experience (article in Chinese). Zhejiang Da Xue Xue Bao Yi Xue Ban 49, 147-157.

151. Gogokhia L, Taur Y, Juluru K, et al. (2020) Intestinal dysbiosis and markers of systemic inflammation in viscerally and generally obese persons living with HIV. J Acquir Immune Defic Syndr 83, 81-89.

152. Carter SJ, Baranauskas MN \& Fly AD (2020) Considerations for obesity, vitamin D, and physical activity amidst the COVID-19 pandemic. Obesity 28, 1176-1177.
153. Gasmi A, Noor S, Tippairote T, et al. (2020) Individual risk management strategy and potential therapeutic options for the COVID-19 pandemic. J Clin Immunol 215, 108409.

154. Barazzoni R, Bischoff SC, Breda J, et al. (2020) ESPEN expert statements and practical guidance for nutritional management of individuals with SARS-CoV-2 infection. Clin Nutr 39, 1631-1638.

155. Lippi G, Henry BM, Bovo C, et al. (2020) Health risks and potential remedies during prolonged lockdowns for coronavirus disease 2019 (COVID-19). Diagnosis (Berl) 7, 85-90.

156. Severin R, Sabbahi A, Mahmoud AM, et al. (2019) Precision medicine in weight loss and healthy living. Prog Cardiovasc Dis 62, 15-20.

157. Yang W, Wang C, Shikora S, et al. (2020) Recommendations for metabolic and bariatric surgery during the COVID-19 pandemic from IFSO. Obes Surg 30, 2071-2073.

158. Tewksbury C, Williams NN, Dumon KR, et al. (2017) Preoperative medical weight management in bariatric surgery: a review and reconsideration. Obes Surg 27, 208-214.

159. Walo-Syversen G, Kvalem IL, Kristinsson J, et al. (2019) Executive function, eating behavior, and preoperative weight loss in bariatric surgery candidates: an observational study. Obes Facts 12, 489-501.

160. Stahel PF (2020) How to risk-stratify elective surgery during the COVID-19 pandemic? Patient Saf Surg 14, 8.

161. Schetz M, De Jong A, Deane AM, et al. (2019) Obesity in the critically ill: a narrative review. Intensive Care Med $\mathbf{4 5}$, 757-769.

162. Laviano A, Koverech A \& Zanetti M (2020) Nutrition support in the time of SARS-CoV-2 (COVID-19). Nutrition $\mathbf{7 4}$, 110834.

163. Mogensen KM, Andrew BY, Corona JC, et al. (2016) Validation of the Society of Critical Care Medicine and American Society for Parenteral and Enteral Nutrition recommendations for caloric provision to critically ill obese patients: a pilot study. $J$ Parenter Enteral Nutr 40, 713-721.

164. Yang JK, Feng Y, Yuan MY, et al. (2006) Plasma glucose levels and diabetes are independent predictors for mortality and morbidity in patients with SARS. Diabet Med 23, 623-628. 